\title{
A Tale of Two Systems: Success and Failure in a Single Information System Implementation
}

\author{
Catherine Middleton \\ OBIR/Schulich School of Business \\ York University \\ 4700 Keele Street \\ North York, Ontario \\ Canada M3J 1P3 \\ E-mail: cmiddlet@bus.yorku.ca
}

Working Paper 20-97

An abstracted version of this paper has been published as:

Middleton, C. A. (1995). A Tale of Two Systems? Success and Failure in a Single Information System Implementation. In M. K. Ahuja, D. F. Galletta, \& H. J. Watson (Eds.), First Americas Conference on Information Systems, (pp. 47-49). Pittsburgh, PA: Association for Information Systems.

http://hsb.baylor.edu/ramsower/acis/papers/cmiddlet.htm 


\section{INTRODUCTION}

This paper presents a case study of an information system implementation. The system, a computerized student record system, was introduced into a small university when the university opened. Unlike many other case studies of systems implementation, there was no existing system to replace, thus it was expected that there would be little resistance to the system. Successful implementation was aniticipated, particularly as the systems designers were also the primary users. An evaluation of the system shows this was not the case. Two groups of users are identified, one pleased with the system, the other dissatisfied. The secondary users did not display their dissatisfaction with the system by resistance, however. They used the system frequently, but were denied the full access they required to do their jobs. Ostensibly due to technical limitations of the system, the primary users acted as gatekeepers. An examination of the culture and management structure of the university reveals strong political motivations for the primary users to exert power over the secondary users. Markus's (1983) interpretation of interaction theory is used to discuss the political implications of the system design. It is concluded that senior management must be aware of the importance of information systems to their organizations, and understand the potential for designers to use these systems as sources of power.

The case study is reconstructed from the author's experiences as a staff member at the university during the system implementation, initially as a primary user of the system (but not an active member of the system design team), and later as a secondary user. The case is evaluated from the perspective of both user groups, using a framework derived from the literature on information systems failure and successful systems implementation. 


\section{THE CASE STUDY}

\section{University Background}

Private University (PU) was a new university. Initially operating from an office building several kilometres from campus, the university consisted of an enthusiastic president, several deans and an assortment of administrative staff. The staff came from a variety of backgrounds, some with extensive university experience, others with virtually none. What they shared was an infectious enthusiasm for the university, which, when they were hired, was simply an idea and a muddy construction site. The university, the first private university in the country, was backed by a successful entrepreneur, but was viewed with great suspicion by the academic community at large. Armed with extensive glossy publicity materials and an abundance of naive optimism, the university set out to recruit its first students to undergraduate programs in business, law, arts and computing.

The environment was an exciting one, where decisions were made quickly, money was spent freely and emphasis was placed on defining the university as an institute of higher education significantly different than those existing in the public sector at the time. In order to support the university's objectives new systems and ways of organizing were required. The administrative staff had a fresh slate on which to sketch out the organizational structure that would allow Private University to meet its objectives.

\section{Selection of the Information System}

One of the early decisions concerned the purchase and installation of a student information system. It was recognized that an information system was an essential administrative tool, thus the search for a suitable product began. Administrative computing systems in the established universities had evolved over

the years. Each university had a system well-tailored to its own institutional needs. The systems did have some common elements that would have suited PU's needs, but billing and admissions, key functions for PU, were not well supported. Unlike other universities, PU charged substantial fees and did not use the state-based university admission centres to process applications for admission. Forced to look beyond 
existing options, PU chose to purchase and install an information system used in many American universities. The registrar's comments sum up the decision process:

All [other] administrative systems were home grown. Most universities had DEC/VAX environments and fairly large computing staff groups with reasonable systems design skills. Unfortunately none of these were recent and, as with all home grown systems, the documentation and support would not have translated well. There were at that time very few real off the shelf items either. We looked at several products, but the truth of the matter was that we analyzed the student system, had a look at 2 Beta sites [in the U.S.], and decided that the SIS [Student Information System] would do the job and well.

\section{Information System Details}

The information system had four components, Human Resources, Financial Records, Student Information and Alumni Information. The Alumni system was not developed initially, as it would be some years before the university had any graduates on which to keep information. Certain elements of the system were common to all components, and some data was shared. Several aspects of the system design and introduction were handled by a joint development group representing finance, personnel and the registrar. Most applications, however, were developed individually by the specific group using them most frequently. The focus of this paper is on the development of the academic administration and student information system. This was the segment of the system most widely used and the only part where the majority of users were not involved in the system design process.

\section{System Implementation and Development}

Private University was in an ideal position for a successful system development and implementation process. The system designers had a free hand, as there was no existing system to attempt to replace. Furthermore, as the university had not yet established routines and administrative procedures, it was expected to be easy to design a system that could accommodate the required procedures. Given the opportunity to design a system simultaneously with the guiding procedures for its use, a successful outcome was anticipated.

The implementation was to follow the progress of the students, with system components becoming available as they were required. Because of the time pressures involved (the systems development started in earnest about eight months before classes were to begin) the initial applicant processing was not done on 
the system. A Macintosh database, developed by an admissions officer and installed on a LAN was used for this purpose, allowing the designers to concentrate on making the enrollment package functional. In addition, class scheduling, class lists, tuition fees, accommodation fees and degree information (e.g. type of degree, program of study) functions were all necessary for the first enrollment period. The system designers were under intense pressure working toward their deadline.

While not modeled on existing systems at public sector universities, it is important to note that the system was not being developed from scratch. Although the university's procedures were not wellestablished, the system itself did provide a generic base model for many of the necessary functions. Nevertheless, there were many changes necessary. Private University's academic structure was a hybrid between American and British models, thus the system required substantial modification and customization.

The system development process was under the jurisdiction of the registrar, and it was his officethat was to be responsible for daily operations, future modifications and maintenance of the system. The development team consisted of three individuals - the assistant registrar, an administrative officer from the registrar's office, and a computer programmer from computing services. The registrar's staff had worked together at their previous jobs at a state-wide university admissions centre, but had had little previous experience in systems development. The computer programmer had little experience in working in a university environment, but had extensive computing knowledge. As the system was a mainframe-based batch operating system programmed in COBOL, the development team needed extensive training to allow customization of functions. Working closely with the registrar to determine administrative procedures, the team spent much time developing the individual components of the system.

\section{Models of Information System Design and Implementation}

Did the design process follow a standard model? The systems design literature provides some generally accepted principles for successful design (e.g. Ackoff, 1967; Senn, 1981; Ginzberg, 1981; Bowman et. al, 1983; Davis and Olson, 1985). A rational design process is recommended. Systems needs must be analyzed, and a strategic plan developed to meet those needs. Decision processes should be flow- 
charted, allowing information requirements at each stage to be well-defined. The first priority is to deal with the aspects of the system that are critical to the organization's operations. The system must be integrated into the managerial processes, and managerial support and involvement must be solicited for the project. Finally, resources must be allocated to the project, and an appropriate methodology chosen to enact the systems design.

These design principles could be achieved by a prototype process or through the more traditional SDLC approach. At Private University, where information requirements were evolving as the system was designed, a prototyping approach would have been preferable. In addition, the users ${ }^{*}$ of the system were willing to participate in the design process, and could have offered useful insights at the prototype stage. However, the need to have a system up and running quickly, and the technical complexity of the system favored the more traditional approach. (See Mahmood, 1987 for a discussion of the two approaches.) The principles of definition, design and implementation guided the process, but were not strictly adhered to.

\section{System Development at Private University}

The bankruptcy of the university's founder, prior to its opening, had abruptly ended the days of lavish spending and left the registrar's office understaffed. As a result, the system was developed by the project team alone, with no input from other users, who were fully occupied with their existing responsibilities. The functions that were being developed initially were ones that would remain within the jurisdiction of the registrar's office, thus the exclusion of other users from the design process was perhaps justifiable.

However, subsequent design stages involved information and processes essential to the faculties and their administration. But by this point, the design process was entrenched, and there was no opportunity for the faculties to have input into the system, or more importantly, into the design of the processes that

"Bostrom and Heinen's (1977) terms primary users and secondary users will be employed here. In this context, the primary users are defined as the system designers and other staff in the registrar's office. Secondary users are the faculty administrators and the marketing staff. 
were being institutionalized by the implementation of the system. The designers, who had legitimate claim to design the first stages of the system, designed the entire system with minimal input from other users.

Users were presented with a finished product, and an indication that the product was not open to change. On their part, users were prepared to accept the system as provided, fully aware that a student record system of some sort was essential to the smooth operation of the university. While users were not overwhelmed by the functionality of the system, neither were they totally disappointed. The system was adequate, but not remarkable.

\section{SYSTEM EVALUATION}

How can this system be evaluated? Did primary and secondary users evaluate the system in the same way? The registrar's office maintained control of the system, and was responsible for all data input, regardless of the nature of the data. Each faculty had an administrator responsible for student matters. These administrators required system access to check student and applicant addresses and personal information, student registration details, student grades and class lists. Read-only access was granted to faculty administrators and to marketing staff who required information on applicants to the university. Faculty and marketing staff could not generate reports, search the database, or download information. The registrar's staff had full access to the database, and were to provide the other users with additional information on request. How did the registrar's staff evaluate the system? Did the other users evaluate it in the same way? Was the system considered a success?

\section{An Investigation of Information Systems Failure}

To answer this question, an understanding of the meaning of information systems failure is needed. Although there is an extensive literature on information systems failure (e.g. Ginzsberg 1981a; Ackoff, 1967; Bostrom and Heinen, 1977; Schmitt and Kozar, 1978; Davis et al., 1992) there is little consensus on a definition. 
From Schmitt and Kozar's (1978) perspective, information systems failure implies the termination of the project. Using this as an evaluation criterion, it would be concluded that the system was a success, as it remained in operation. However, other criteria would challenge this conclusion.

Davis et al. (1992) suggest that "a sufficient condition for indicating the occurrence of a failure is that the organizational participants who have a stake in the information system (something to gain from the success of the information system or something to lose as a result of its failure) agree that the system is a failure". There was no consensus in this respect. The registrar's staff believed it was an excellent system. Indeed, the registrar stated "[The assistant registrar] and I really think that for a system grown from a batch processing approach and written in COBOL it was remarkably good, particularly as it had built into it everything we needed".

On the other hand, the secondary users were constantly frustrated by the system. It was somewhat cumbersome to navigate, in that checking records often required more than one screen. Furthermore, without on-line search capability the administrator could not pull up lists of students enrolled in specific degree programs, or students holding scholarships, for example. The information was presented on screens, with each screen showing information for one record only. Printing capability was limited to printing each screen as it was displayed. These system characteristics led faculty users to disagree with the registrar's assessment of the system.

Senn (1981) points to user resistance as symptomatic of system failure. For example, he indicates that users may aggressively attack the system, rendering it unusable or ineffective, or they may simply avoid using the system. PU's faculty administrators could not avoid using the system, but infrequent users often chose to telephone the registrar's office to get the information they required, rather than log into the system. In spite of some resistance from users, there was no outright refusal to use the system. The system could not be considered an outright failure according to Senn's criteria. In fact, secondary users indicated their dissatisfaction by requesting additional access to the system.

Ginzberg (1981a) lists causes of failure as user dissatisfaction with system scope, system goals or the general approach to the problem the system was to address. He also suggests systems are more likely to fail 
when they are introduced with unrealistic expectations. However, in the case of the SIS implementation, there were very few expectations instilled on the part of the users. The primary users had met their expectations in designing the system and were happy with its goals. The secondary users had limited understanding of the true capacities of the system, and had few expectations regarding its performance. They failed to embrace the system, but accepted it as a fait accompli.

Another cause of systems failure is the misspecification of the design referent group or user. Bostrom and Heinen (1977) refer to the instance of the system being designed for the top level manager, leaving the secondary users with a system that does not meet their needs. A problem with the design process at PU was that the principal designers were also users. Intuitively, this should not cause trouble, considering that user involvement is prescribed by many researchers as a way to mitigate user dissatisfaction (see Ives and Olson, 1984, for discussion on this topic). The difficulty with the PU systems designers was that they assumed that a design meeting their own needs would also satisfy all other users. This underscored a fundamental problem with the design and implementation -- a failure (or refusal) to recognize the needs of the secondary users of the system.

\section{Criteria for Successful Systems Implementation}

How does the system fare when evaluated using criteria for system success? The literature on factors that lead to successful system design and implementation is similar to that on systems failure, in that there is no consensus on the elements of successful system design. DeLone and McLean (1992) outline six dimensions of successful information systems. These are quality of the information system, quality of the information produced by the system, use of the information produced by the system, user satisfaction with the system, the individual impact of the information generated upon management decisions, and the impact of this information upon organizational performance. How would these factors be assessed by the two user groups at PU?

As had been indicated previously, the registrar and his staff thought the information system was "remarkably good". However, there were numerous technical limitations that frustrated secondary users in their attempts to use the system. Although the network was technically reliable, the number of users on the 
system at any one time was limited, meaning it was not always accessible. Furthermore, the registrar's staff could, and frequently did, lock users out of the system.

The quality of the information the system produced was a function of the format in which it was provided. As faculty users could not write reports, they were dependent on the registrar's staff to provide information. Often the information was provided in unwieldy reports which required much additional work on the part of the faculty in order for it to be useful. As Ackoff (1967) suggests, the problem was not with a lack of information, but rather an "over abundance of irrelevant information", in this instance in report format.

The information system contained information on applicants that was of strategic importance to the university's marketing and admissions functions. The marketing office, however, had access privileges to the system similar to those of faculty officers, meaning that they could not generate their own reports, or gather and analyze information in the way they preferred. Despite the importance of the marketing function, it was unable to get admissions information on demand, thus the strategic value of the admissions database was not exploited by the marketing management. However, for the purposes of planning class schedules, for example, the registrar was able to use the information effectively by generating reports tailored to that purpose. Thus, in some instances, system information did have an impact on management decisions.

In terms of organizational performance, PU was held back on several fronts by the information system. In the first years of the university's operation, the primary source of funding (for all university activities) was tuition fees. In this austere environment, enrollments were crucial. The marketing and admissions areas experienced intense pressure from the university council and from the senior staff to generate new enrollments. In order to provide personal service to prospective students it was essential that the admissions representatives had full access to the application records. Restricting access to these records was an example of the negative impact of the information system upon the organizational performance.

Pollalis and Frieze (1993) re-examined the traditional notion of critical success factors in information technology, suggesting the key factors are:

- delivery of good services

- alignment of IS priorities with those of the whole organization 
- support from senior management

- communication between IS executives and key IS users

- insurance that IS services evolve to meet organizational needs and capabilities

These factors overlap with others previously discussed. However, the issue of top management support has not been fully considered, nor has the question of the system's capacity to evolve and change with the organization.

At PU, the senior management was unfamiliar with the student information system. The registrar was strongly supportive of his staff's development efforts, but the university president and faculty deans knew little about the system. The marketing director knew the value of the information contained within the system, and realized his staff required full access. However, the system was not within his jurisdiction, and as other senior managers were unaware of the system's strategic importance, his opposition went unheard.

In customizing the system for PU's needs, decisions were made regarding data structures that made subsequent change difficult. However, with access to report writing facilities, most structural difficulties could be overcome. Primary users could easily accommodate changing requirements, but secondary users were reliant upon the registrar's office for help in managing evolving information needs.

\section{Two Perspectives on Private University's Information System}

The preceding discussion on criteria with which to evaluate the system shows two vastly different assessments of the system's performance. The system designers and primary users had control over the system and considered it to be a success on most criteria. In stark contrast, the staff in the faculties and the marketing office viewed the system as inadequate and unresponsive to their needs. From their perspective, the system was a failure. The opinions of the two user groups on each criterion are summarized below. 


\begin{tabular}{|c|c|c|c|c|}
\hline Evaluation Criterion & $\begin{array}{l}\text { Primary Users } \\
\text { Perspective }\end{array}$ & $\begin{array}{l}\text { Secondary } \\
\text { Users } \\
\text { Perspective }\end{array}$ & $\begin{array}{l}\text { Primary Users } \\
\text { Assessment }\end{array}$ & $\begin{array}{l}\text { Secondary } \\
\text { Users } \\
\text { Assessment }\end{array}$ \\
\hline Was the project terminated? & No & No & Success & Success \\
\hline $\begin{array}{l}\text { Was it agreed that the project was a } \\
\text { failure? }\end{array}$ & No & Uncertain & Success & Uncertain \\
\hline Did the users resist the system? & No & Yes & Success & Failure \\
\hline $\begin{array}{l}\text { Were the users satisfied with the } \\
\text { system's scope? }\end{array}$ & Yes & Uncertain & Success & Uncertain \\
\hline $\begin{array}{l}\text { Was the system designed to meet } \\
\text { users' needs? }\end{array}$ & Yes & No & Success & Failure \\
\hline $\begin{array}{l}\text { Was the quality of the information } \\
\text { system acceptable? }\end{array}$ & Yes & Not entirely & Success & Failure \\
\hline $\begin{array}{l}\text { Was the information produced by } \\
\text { the system of acceptable quality? }\end{array}$ & Yes & Sometimes & Success & Failure \\
\hline Was the information used? & Yes & Not always & Success & Failure \\
\hline $\begin{array}{l}\text { Did the information impact upon } \\
\text { management decisions? }\end{array}$ & Yes & Sometimes & Success & Failure \\
\hline $\begin{array}{l}\text { Did the information impact } \\
\text { organizational performance? }\end{array}$ & Yes & $\begin{array}{l}\text { Lack of } \\
\text { information had } \\
\text { a negative } \\
\text { impact }\end{array}$ & Success & Failure \\
\hline $\begin{array}{l}\text { Did senior management support the } \\
\text { system? }\end{array}$ & Yes & No & Success & Failure \\
\hline $\begin{array}{l}\text { Was the system able to evolve with } \\
\text { a changing organizational } \\
\text { environment? }\end{array}$ & Yes & Uncertain & Success & Failure \\
\hline
\end{tabular}

\section{ANALYSIS}

From the perspective of the registrar's office, the system was clearly successful. But for the staff in the faculty and marketing offices, the system was generally considered a failure. The system did provide the secondary users with some basic functionality. It was this functionality that was branded a success by the registrar's staff, but they failed to understand or accommodate the extended needs of the other users. It appears that the registrar's office provided the secondary users with a transaction processing system when what they required was a management information system. The users were not satisfied by the functionality 
of the TPS alone, because they understood the additional value in using the information for decisionmaking, not just record keeping.

Was the misfit between the secondary users' system requirements and the system they actually had access to an intentional misfit? Was it the result of poor planning and inexperience on the part of systems designers? Was it because of the technical limitations of the system?

The designers' reluctance to allow others access to report writing facilities initially was justifiable. The system was somewhat complicated to use, and the designers were under pressure to provide an operational system for the university's opening day. Had they decided to provide access to report writing facilities for the secondary users, extensive training would have been required. As most secondary users were new to their jobs at that stage, they had only a limited grasp of the value of the system and would not have benefited fully from the training sessions.

Once the university was operational however, the secondary users required management information from the student database. It was not impossible to obtain the information, but it was inconvenient, and the information received did not always match the information requested.

Users were led to believe that the system was very technical in nature, and thus they did not demand access to it immediately. The developers allowed users no access to the system documentation, thereby perpetuating the myth of technical complexity and discouraging them from learning the true capabilities of the system. The control that the developers exerted over system access is indicative of one of Bostrom and Heinen's (1977) conditions of faulty systems design. Bostrom and Heinen suggest that systems designers hold a Theory X view of the system users. (McGregor's Theory X suggests that people will not take responsibility for their actions, make independent decisions, seek guidance at all times and must be coerced into achieving goals.) This assumption appears to have been held by the systems designers, as evidenced by their refusal to accord users the necessary access privileges for effective system use.

Did the registrar's staff refuse to allow unrestricted system access because they felt secondary users were incapable, or was there another motive? The registrar's staff was extremely busy developing and implementing administrative procedures and academic policies. By allowing the secondary users access to 
the database a portion of their own workload would have been reduced. The secondary users were not looking for access to change the information held in students' records, they merely required access to it for administrative purposes. (For example, faculties would be provided with printed class lists at the beginning of each semester. Although these were generated by the system, faculty members had to re-type them from the list into their own computers if they wanted electronic records of their students.) To the faculties it was incomprehensible that the registrar would not allow them access to information in the format they required, when they needed it, as it would reduce the workload on the administrative staff.

To understand this apparent paradox, it is instructive to consider the structure of the university, and to understand the implications of funding a university on tuition fees alone. The university's governing body, the university council, was chaired by the chancellor. The day to day operations were handled by the president, with an advisory committee of deans and office directors known simply as the senior staff. The university was small (less than 350 students in its inaugural semester), and it did not have a senate or policy-making committees. Decisions were made at the senior staff level, with the president as the final arbiter.

The organizational chart shows the faculties and administrative functions that made up the university. What it also shows, indirectly, is the division between revenue generators and expense generators. Tuition revenues were provided by the faculties. Although the support services of the offices were essential in generating enrollments, the administrative offices were considered cost centres, not profit centres. When the university's governing structure had been established there was no shortage of funds. Faculties worked in close cooperation with the administration, sharing the common goal of excellence in education. Once the funding crisis became evident however, there was a split in the ranks. As the revenue generators, the faculties became critical of the expenses generated by the administration, and demanded significant cuts in administrative staffing levels. Administrative managers effectively lost control of their budgets, forced to comply with the faculties' wishes. The centralized nature of the university's administrative structure came under fire, with the faculties suggesting that they could provide the services offered by the central administration on their own. 
PRIVATE UNIVERSITY ADMINISTRATIVE STRUCTURE

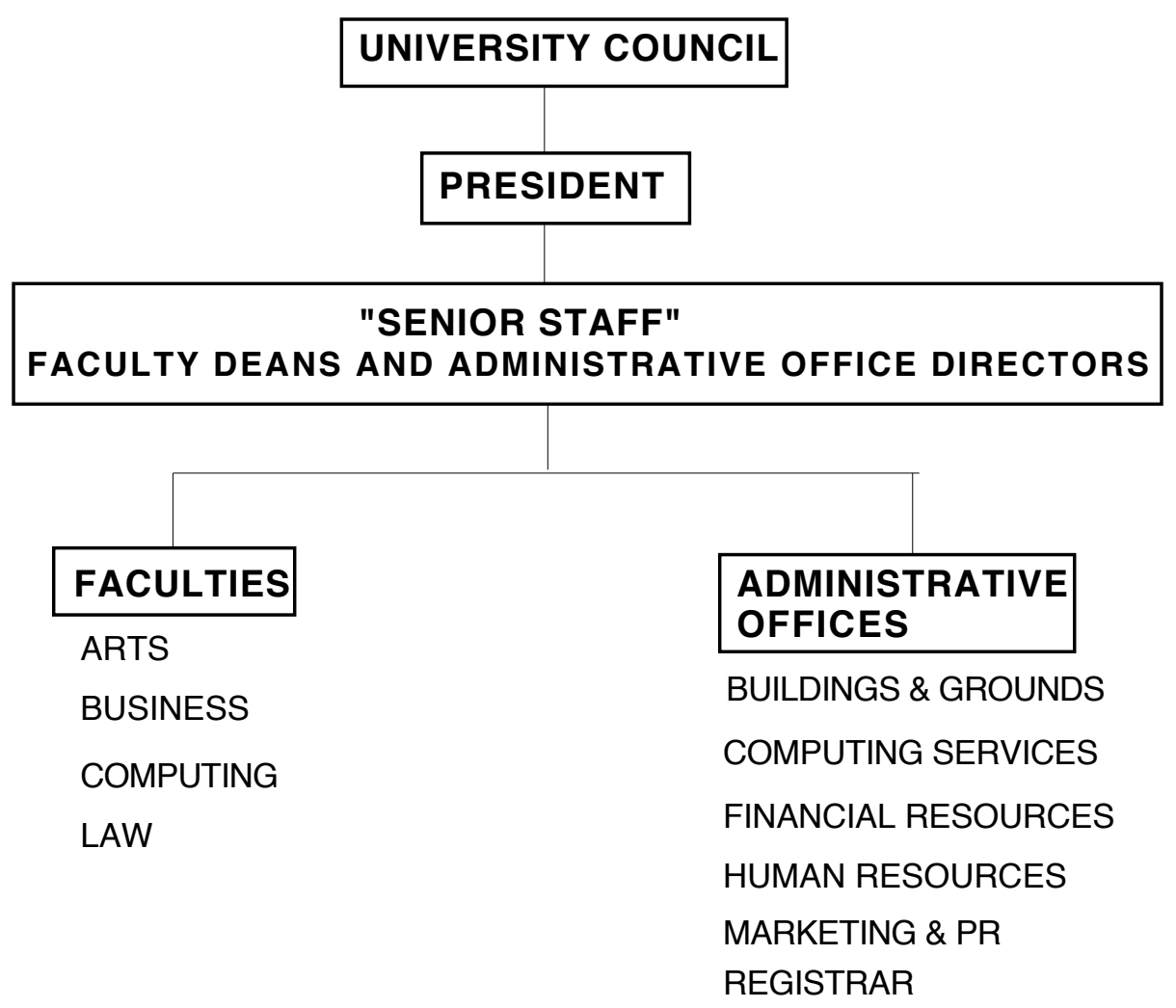

The administrators were defenseless. In most instances they had little choice but to comply with the faculties' requests. The student information system was one area where they could hold their own. The deans were generally unaware of the system's capabilities, and despite pleas from their staff to gain more control over the system, they showed little interest in its management. It was this lack of interest that allowed the registrar's staff to use the information system as a potent political tool.

By maintaining control of the system and continuing to limit access to its information, the registrar's staff became indispensable. Granted, there was a need for central maintenance of student information, a function performed by the registrar's office. However, it was not control of the system that the secondary users sought. They simply sought access to the information. In denying this access the registrar's staff created a power base. Unlike other functions performed by the administration, this was one that the faculties could not decentralize, thus they were subjected to the power plays of the registrar's staff. 


\section{A Political Perspective on the System Development}

Markus' (1983) use of interaction theory to examine the political aspects of systems design is instructive here. She builds her theory from Kling's (1980) theoretical work on technology and organizations. Although Markus discusses the theoretical base of user resistance to systems, her observations hold true for the situation of IS failure due to restricted system access at PU.

Interaction theory suggests that IS failure is "because of an interaction between the characteristics related to the people and characteristics related to the system". It is observed that there are no inherent power implications in the IS used at PU. The system installation focused on customization of a standard package. It was in determining access privileges to the system that power issues arose. As gatekeepers (Bjørn-Andersen and Petersen, 1980) for the system, the primary users could exert power over the secondary users, power that could not otherwise be derived from their position in a non-revenue generating office.

The registrar's office suggested that access to the system had to be denied for technical reasons, yet there was a simple report writer they themselves used to generate the data requested by secondary users. There was no need to understand COBOL programming to access data, but if the data was easily accessible the primary users would have ceded their sole source of power.

Markus and Bjørn-Andersen (1987) discuss the exercise of power by IS professionals over users. This is precisely what occurred at PU. Markus and Bjørn-Andersen could be describing the design team, in noting:

IS professionals exercise power over user behavior by creating organizational structures and routine operating procedures that give them formal authority over users or foster user dependence on them for important resources.

Structural power was built into the system by the designers when they determined access privileges. 


\section{CLOSING COMMENTS}

What can be learned from this case study? It is clear that systems designers can exert significant power over users through the structure of system/organization interaction. The power exerted at PU was not a function of the technology employed, but of organizational politics. An examination of the implementation of the same system in different environments would likely reveal very different outcomes.

The systems designers were able to use the system as a political tool because the senior managers were unaware of its importance or its potency. This case highlights the necessity for senior management to understand the technology implemented in their organizations. As Ackoff (1967) notes, "No MIS should ever be installed unless the managers for whom it is intended are trained to evaluate and hence control it, rather than be controlled by it".

This case also shows that information systems should fit the environment in which they operate. The gatekeeping function of the system was not appropriate in an atmosphere where all offices had to be responsive to faculties and marketing needs. The university needed a system that encouraged the users to work together towards its common goals, rather than one that allowed a group of users to play political games and exert power over a second group. 


\section{REFERENCES AND RELATED READING}

Ackoff, R. L., "Management Misinformation Systems", Management Science, 14: 4, 1967, pp. B147B156.

Bjørn-Andersen, N. and P. H. Pedersen, "Computer Facilitated Changes in the Management Power Structure", Accounting, Organizations and Society, 5: 2, 1980, pp. 203-216.

Bostrom, R. P., and J. S. Heinen, "MIS Problems and Failures: A Socio-Technical Perspective, Part 1 The Causes", Management Information Systems Quarterly, 1, 1977, pp. 17-32.

Bowman, B., G. Davis and J. Wetherbe, "Three Stage Model of MIS Planning", Information and Management, 6, 1983, pp. 11-25.

Davis, G. B. and M. H. Olson, Management Information Systems: Conceptual Foundations, Structure , and Development, New York: McGraw-Hill, 1985.

Davis, G. B., A. S. Lee, K. R. Nickles, S. Chatterjee, R. Hartung and Y. Wu, "Diagnosis of an Information System Failure", Information and Management, 23, 1992, pp. 293-318.

DeLone, W. H. and E. R. McLean, "Information Systems Success: The Quest for the Dependent Variable", Information Systems Research, 3: 1, 1992, pp. 60-95.

Ginzberg, M. J. "Early Diagnosis of MIS Implementation Failure: Promising Results and Unanswered Questions", Management Science, 27: 4, April 1981,pp. 459-478. (1981a)

Ginzberg, M. J. "Key Recurrent Issues in the MIS Implementation Process", Management Information Systems Quarterly, 5: 2, June 1981, pp. 47-60. (1981b)

Ives, B. and M. H. Olson, "User Involvement and MIS Success: A Review of Research", Management Science, 30: 5, pp. 586-603.

Kling, R., "Social Analyses of Computing: Theoretical Perspectives in Recent Empirical Research", Computing Surveys, 12: 1, March 1980, pp. 61-110.

Markus, M. L. and N. Bjørn-Andersen, "Power Over Users: Its Exercise by System Professionals", Communications of the ACM, 30: 6, June 1987, pp. 498-504.

Markus, M. L., "Power, Politics, and MIS Implementation", Communications of the ACM, 26: 6, June 1983, pp. 430-444.

Pollalis, Y. A. and I. H. Frieze, "A New Look at Critical Success Factors in IT", Information Strategy: The Executive's Journal, Fall 1993, pp. 24-34.

Schmitt, J. W. and K. A. Kozar, "Management's Role in Information System Development Failures: A Case Study", Management Information Systems Quarterly, June 1978, pp. 7-16.

Senn, J. A., "Essential Principles of Information Systems Development", Management Information Systems Quarterly, June 1978, pp. 17-26. 